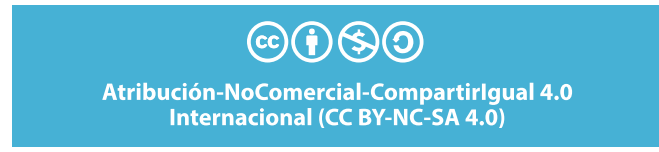

DOI: http://dx.doi.org/10.20983/reij.2021.2.3
Héctor Joaquín Bolio Ortiz ${ }^{1}$

Juan Pablo Bolio Ortiz

\title{
EL SISTEMA SOCIO-JURÍDICO EN LA GOBERNACIÓN DE YUCATÁN DURANTE LA ÉPOCA COLONIAL
}

\author{
The socio-legal system in the government of Yucatan during the colonial period
}

"Si el derecho vive en el tiempo, si el tiempo es una característica constitutiva del derecho, comprender éste quiere decir comprenderlo como historia"

Mario Bretone

\section{Resumen:}

Este artículo nos presenta el panorama social y demográfico de la gobernación de Yucatán durante la época colonial. El objetivo del trabajo es tener una imagen mucho más clara del componente social, cultural y político en el territorio conquistado, así como sus cambios y continuidades durante los siglos XVI, XVII y XVIII. La metodología que se emplea es de corte cualitativo y se sustenta en el método de la larga duración histórica en la cual traza una línea en el tiempo que abarca la época colonial. La hipótesis es que la sociedad yucateca colonial fue heterogénea y se sustentó en diferentes estatutos jurídicos. Los resultados del trabajo nos demuestran que la población en Yucatán sufrió grandes cambios debido a coyunturas como la conquista, guerras, epidemias y calamidades, logrando una recuperación lenta para el siglo XVIII.

Palabras clave: estatutos jurídicos, sociedad, población.

\section{Abstract:}

This article presents the social and demographic panorama of the Government of Yucatan during the colonial era. The objective of the work is to have a much clearer picture of the social, cultural and political component in the conquered territory, as well as its changes and continuities during the sixteenth, seventeenth and eighteenth centuries. The methodology used is qualitative and is based on the method of long historical duration in which it draws a line in time that covers the colonial era. The hypothesis is that colonial Yuca-

1 Héctor Joaquín Bolio Ortiz, es licenciado en Derecho por la UADY, maestro en Trabajo Social por la UNAM, maestro en Desarrollo Regional por el Tecnológico Nacional, doctor en Ciencias Sociales, está adscrito al Instituto Electoral y de Participación Ciudadana de Yucatán, es miembro del Sistema Nacional de Investigadores y del Servicio Profesional Electoral Nacional, México, boliojuridico@gmail.com, orcid: 0000000177568858.

2 Juan Pablo Bolio Ortiz, es licenciado en Derecho por la UADY, maestro y doctor en Historia por el CIESAS, está adscrito al Instituto Electoral y de Participación Ciudadana de Yucatán, es miembro del Sistema Nacional de Investigadores y del Servicio Profesional Electoral Nacional, México, boliojuridic@hotmail.com, orcid: 0000000168685585. 
tecan society was heterogeneous and was based on different legal statutes. The results of the work show us that the population in Yucatán suffered great changes due to situations such as the conquest, wars, epidemics and calamities; achieving a slow recovery for the eighteenth century.

Keywords: legal statutes, society, population.

\section{Introducción}

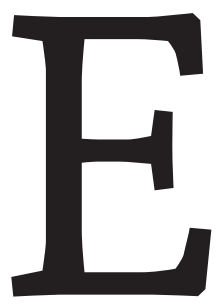

n este trabajo se expone la conformación social y demográfica de Yucatán en tiempos coloniales, cuya complejidad se deriva de la composición heterogénea de la sociedad y de las diferentes jurisdicciones que no fueron estáticas. Las autoridades en la gobernación de Yucatán fueron variadas y a la cabeza, como máximo depositario del poder político en la provincia estaba el gobernador, quien desde luego se supeditaba al rey y a diversas instancias como la Real Audiencia de México o de Guatemala, según el momento y el Consejo Real y Supremo de Indias. La Gobernación se conformó por los actuales estados mexicanos de Yucatán, Campeche, Quintana Roo y Tabasco, así como parte del actual territorio de Belice. Es por eso que resulta importante para entender diferentes temáticas en torno a la historia de Yucatán, conocer el conglomerado de personas que formaron una sociedad compuesta de indios, españoles, negros y diversas castas. En este sentido, nuestra hipótesis consiste en que la sociedad yucateca colonial fue heterogénea y se sustentó en diferentes estatutos jurídicos.

¿Cuáles fueron los derechos de las personas ante las autoridades e instituciones? ¿Qué tan heterogénea fue la sociedad yucateca de la colonia? Estas son las preguntas que el presente artículo pretende responder. Lo que guio la investigación que presentamos fue la búsqueda y análisis de la articulación de hechos sociales y políticos, 
para comprender cómo las apropiaciones particulares y colectivas de una sociedad compleja dependieron en gran medida de usos y significados impuestos por el entrecruzamiento de una nueva cultura y el ejercicio del poder político implantado por la Corona Española.

Para entender los procesos culturales y sociales de una población es imprescindible entenderlos desde la metodología de la historia de larga duración; es decir, aquella que como diría Braudel "lo que el historiador de las civilizaciones puede afirmar, mejor que cualquier otro. Es que las civilizaciones son realidades de muy larga duración”, por ello para entender problemas actuales tanto desde el derecho, antropología, sociología u otros temas recientes de la sociedad yucateca, es fundamental comprenderlos con la forma de historiar de la larga duración, concepto que a propuesta de Braudel es un puente de comunicación entre las diferentes disciplinas de las ciencias sociales 3 . Es decir, tomando en cuenta los procesos cíclicos y diferentes variaciones que pudo sufrir la sociedad en Yucatán.

\section{Contexto histórico y económico}

La sociedad maya, uno de los grupos humanos que vivieron durante el periodo prehispánico en el área mesoamericana,

3 Braudel, Fernand, Aportación de la historia de las civilizaciones. La historia y las ciencias sociales (Madrid: Alianza, 1968), 187. estuvo en contacto por primera vez con los ibéricos en 1502, cuando Bartolomé Colón se encontró por la Isla Guanaja una canoa pretendida de comerciantes mayas.

La Península de Yucatán fue descubierta en 1508 por Juan de Solís y Vicente Yáñez de Pinzón. En 1511 Gonzalo Guerrero y Gerónimo de Aguilar sobrevivieron a un temporal y se quedaron en territorio yucateco. La costa de Yucatán fue explorada tiempo después por las expediciones de Francisco Hernández de Córdoba en 1517, Juan de Grijalva en 1518 y Hernán Cortés en 1519. Cortés se situó en Cozumel donde rescató a Gerónimo de Aguilar, quien posteriormente sirvió de intérprete en la campaña de conquista de México. El otro náufrago, Gonzalo Guerrero, continuó viviendo entre los mayas habiéndose casado con la hija del cacique de Chetumal.

En 1527, el adelantado Francisco de Montejo comenzó la expedición en Yucatán, la cual se fundamentó en las capitulaciones de 1526 donde se le otorgaban una serie de derechos y beneficios en su empresa de conquista. Después de dos campañas fallidas, la conquista fue consumada por el hijo y sobrino del mismo nombre. Francisco de Montejo hijo "el Mozo", fundó el 6 de enero de 1542 sobre las ruinas del antiguo centro ceremonial de Th'o la ciudad de Mérida, nombre que le fue dado en recuerdo de la Emérita de Extremadura.

En el proceso de colonización se dio una dominación de corte militar, política, ideo- 
Figura 1. Mapa de la Península de Yucatán

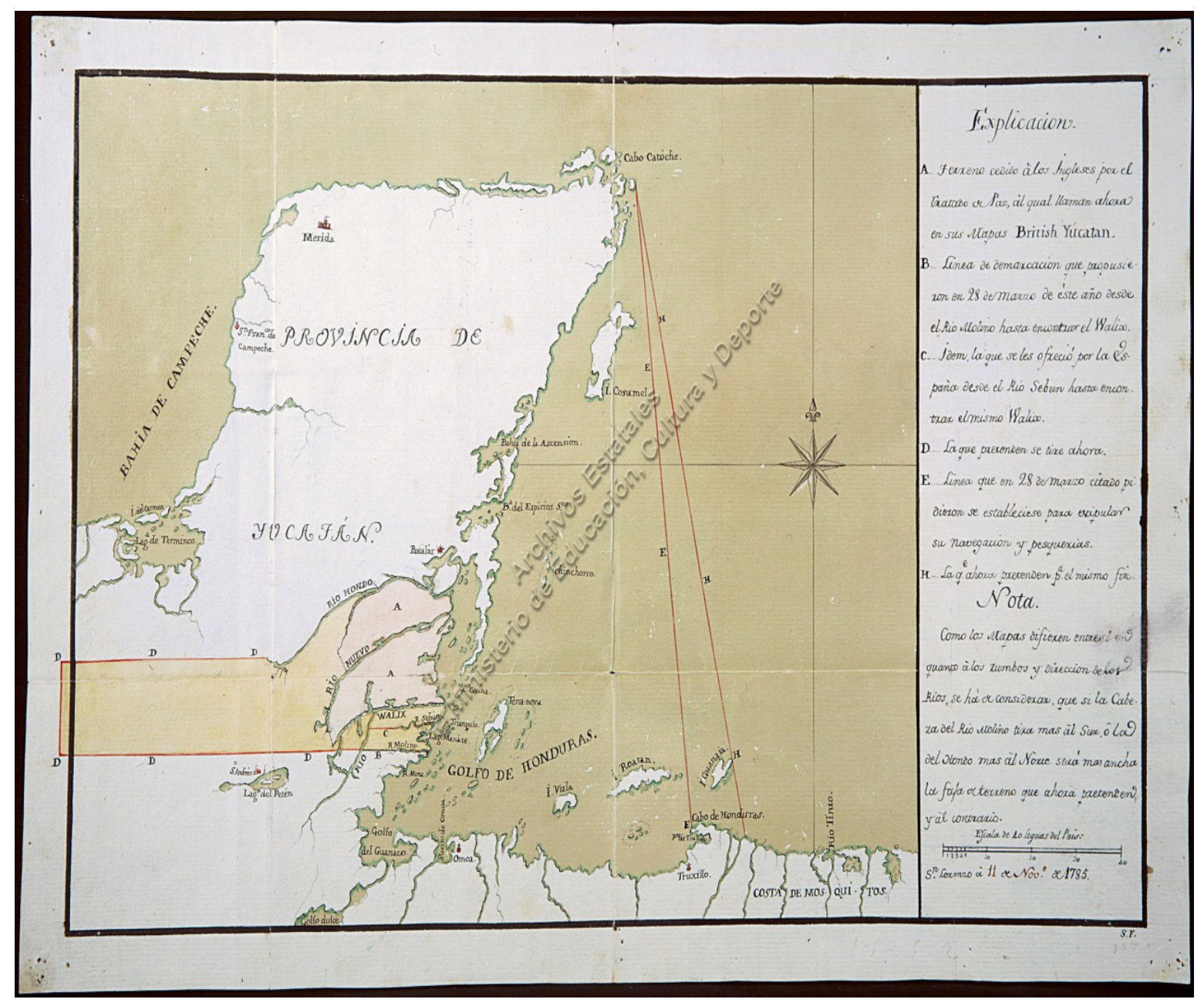

Fuente: AGI, MP-México 399.

lógica y religiosa. La iglesia asumió un papel fundamental para normar la vida de la población conquistada, papel que ha sido observado por Gabriela Solís en términos de tres ejes temáticos de gran transcendencia que se resumen en: a) el proceso de evangelización y la implantación de la Iglesia como institución, b) el conjunto de adaptaciones, adopciones y sobrevivencias en la vida religiosa indígena, c) el vínculo estrecho entre la fundación y es- tablecimiento de la Iglesia provincial y la sujeción indígena. ${ }^{4}$

Para 1546 la Península parecía totalmente conquistada, Campeche en el occidente, Mérida en el centro-norte, Valladolid en el oriente y Bacalar en el suroriental. Aunque se logró la fundación de estas poblaciones, la conquista de los mayas fue un

4 Gabriela Solís Robleda, Bajo el signo de la compulsión: El trabajo forzoso indígena en el sistema colonial yucateco 1540-1730 (México: INAH/CIESAS/Instituto de Cultura de Yucatán/ Miguel Ángel Porrúa, 2003), 6-7. 
asunto de larga duración con huidas y rebeliones constantes; situación analizada por Pedro Bracamonte y a lo que llamó un "pacto colonial", donde los dirigentes mayas de Yucatán se organizaron junto con los conquistadores españoles, utilizando ambos bandos todos los resquicios que permitía el sistema durante tres siglos coloniales, desde la defensoría de indios, las alianzas con grupos de españoles, las huidas a la montaña, las rebeliones, los juicios de residencia, entre otros. ${ }^{5}$ Un espacio complejo, donde tuvieron que convivir los ordenamientos jurídicos castellanos, los de la Iglesia y el derecho consuetudinario del pueblo maya.

En efecto, el atractivo de las Indias era muy poderoso al ofrecer las riquezas más grandes del mundo -reales e imaginariasy ese atractivo era alimentado por aquellos que emigraron con éxito y escribieron a parientes y conocidos animándolos a reunirse con ellos. Obviamente el oro y la plata de las Indias significaron una fortuna inesperada para España. El sistema económico que definiría Adam Smith como mercantilista, es una teoría del enriquecimiento de las naciones mediante la acumulación de metales preciosos. ${ }^{6}$

Las mercancías fluyeron a Sevilla en grandes y cada vez mayores cantidades y

5 Pedro Bracamonte y Sosa, La conquista inconclusa de Yucatán: los mayas de las montañas, 1560-1680 (México: CIESAS, Miguel Ángel Porrúa, 2001), 25.

6 Moisés Gómez Granillo, Breve historia de las doctrinas económicas (México: Esfinge, 1996), 26. las que no salieron de España nada más llegaron para pagar deudas a banqueros extranjeros, convirtiéndose en ganancia de una variada cantidad de individuos. ${ }^{7}$

Sin embargo, la Península de Yucatán careció de los principales elementos de atracción: metales preciosos y tierras aptas para cultivos comerciales. Formada por una plataforma calcárea que emergió en el Mioceno y el Plioceno, durante el Terciario, el territorio norte yucateco es prolongación de roca caliza cubierta con una delgada capa de tierra. La fisiografía está dada por una gran extensión llana, con relieves relativamente suaves, menores de 400 metros, observándose una gradiente altitudinal de las costas hacia el centro de Yucatán, donde se encuentran las máximas alturas en la Sierra Puc. Debido a sus características geográficas no hay ríos en la parte norte, es por eso por lo que los mayas desarrollaron sistemas hidráulicos aprovechando el uso de cenotes y el régimen de lluvias. ${ }^{8}$

Si bien se ha señalado la supuesta pobreza de la tierra en la Península de Yucatán, durante milenos los hombres asentados en ella construyeron un sistema productivo agrícola, de cultivo anual, que tuvo como eje primordial el maíz. Tal sistema se articuló con el conocimiento detallado

7 Jhon Elliot, España y su mundo, 1500-1700 (Madrid: Alianza, 1991), 33-43.

8 Laura Caso Barrera, Caminos en la selva. Migración, comercio y resistencia. Mayas yucatecos e itzaes, siglos XVII-XIX (México: COLMEX, Fondo de Cultura Económica, 2002), 65. 
de los ciclos climáticos y los tipos de suelo y vegetación.

La milpa fue el centro de dicho sistema, bastante complejo, que abarcaba la producción y el consumo de bienes. El policultivo propio de la milpa dependió de un conjunto de conocimientos, como son los distintos suelos, vegetaciones, las variedades de semillas de maíz, los tiempos de germinación, las condiciones climáticas a lo largo del año, las características de los cultivos asociados (frijoles, calabazas, chiles y otros) y los métodos de sembrar. Los mayas también cultivaron algodón, cacao, hortalizas, árboles frutales y tubérculos, entre otros productos, y criaron animales. ${ }^{9}$

Las Relaciones histórico-geográficas describieron las características físicas de Yucatán como:

Tierra caliente y seca, las lluvias comienzan en mayo y terminan en agosto, los principales productos son: el maíz, chile, frijoles y algodón. El viento ordinario es noreste que llamamos brisa, hay vientos fríos y que vienen del mar, causan enfermedades y muertes, y es cosa ordinaria morir más gente entrando los nortes. Algunos años son tan violentos que derriban casas de indios, esto redunda en grandes años de hambres. Esta tierra es llana, muy áspera y pedregosa. El agua que se bebe en esta ciudad y en todas es-

9 Pedro Bracamonte y Sosa, La conquista inconclusa de Yucatán: Los mayas de las montañas, 1560-1680 (México: CIESAS, Miguel Ángel Porrúa, 2001), 26. tas provincias es de pozos, hay cantidad de pozos llamados cenotes. ${ }^{10}$

En la novena ordenanza emitida por el oidor de la Audiencia de México Diego García de Palacio se estipulaba:

Ítem mando a los dichos gobernador y alcaldes hagan que todos los naturales tengan buenas casas desmontadas alrededor, limpias y bien aderezadas, con buenas barbacoas donde ellos y sus hijos han de dormir, altas y bien hechas, y que críen cada uno doce gallinas de Castilla y un gallo, de la tierra (guajolotes), seis gallinas y un gallo, por manera que en todo tengan mucho cuidado, más de lo que hasta aquí han tenido, y en cada uno de los meses del año uno de los alcaldes del dicho lugar, con un regidor, por su turno, visiten las casas y lo que así criaren, castigando al que no cumpliere lo que en este ordenanza se contiene. ${ }^{11}$

Finalmente, los mayas se vieron obligados a vivir en pueblos trazados según modelos españoles, "en no pocas áreas la aceptación fue en buena medida superficial, a más de que idearon numerosas estrategias para resistir al embate con las antiguas formas de organización social,

10 Mercedes de la Garza, Relaciones histórico-geográficas de la gobernación de Yucatán (México: UNAM, Fuentes para el estudio de la cultura maya, 1983), 69-72.

11 Diego García de Palacio, Visita de Diego García de Palacio a Yucatán 1583 (México: UNAM, 2009), 253. 
en aspectos como los patrones familiares y el tipo de residencia”, pues estaban conscientes de que los cambios traerían consigo mayor explotación social. ${ }^{12}$

Por otro lado, los españoles, una vez que sometieron a las poblaciones mayas, tomaron una serie de medidas para adecuar los patrones sociales a su propia manera de organización y lograr de esta manera que los nuevos vasallos de la Corona viviesen a la usanza occidental. Para ello, conjuntaron esfuerzos las autoridades civiles y eclesiásticas. ${ }^{13}$ La zona de ocupación española se concentró en las principales poblaciones: Mérida, Campeche, Bacalar y Valladolid.

Debido a la ausencia de metales preciosos y las características geográficas y climáticas de la Península, poco adecuadas para el desarrollo de empresas productivas españolas, la sociedad colonial que se gestó en Yucatán compensó la ausencia de los principales elementos de atracción para el desarrollo de la colonización con una población abundante y se implantó un sistema mercantil altamente dependiente de las repúblicas de indios. ${ }^{14}$

12 Mario Humberto Ruz Sosa, "Nombrar para habitar: la morada maya en las grafías coloniales”, en Concepción, factura y atributos de la morada maya, de Fabienne de Pierrebourg y Mario Humberto Ruz Sosa, editado por Otoch Nah, (Izamal: UNAM, SEGEY, 259. Izamal: UNAM, SEGEY, 2014).

13 Mario Humberto Ruz Sosa, Yucatán: un universo peninsular. El mundo colonial, tomo 2 (México: SEP, UNAM, CEPHCIS, 2009), 29.

14 Gabriela Solís Robleda, Bajo el signo de la compulsión. El trabajo forzoso indígena en el sistema colonial yucateco 1540-1730 (México: INAH/CIESAS/Instituto de Cultura de Yucatán/ Miguel Ángel Porrúa, 2003), 11-13.
Políticamente Yucatán fue una Gobernación, la cual estuvo constituida por los actuales tres estados que conforman la Península yucateca, e incluyó también Tabasco y el norte de Belice. ${ }^{15}$ Los gobernadores de Yucatán administraron un territorio amplio, con tenientes de gobernador en Valladolid, Campeche y un alcalde mayor en la capital de Tabasco (sucesivamente Santa María de la Victoria, Tacotalpa de la Real Corona y San Juan Bautista de Villahermosa).

De 1561 a 1565 la máxima autoridad provincial ostentó el título de alcalde mayor, en 1565 el título se volvió de gobernador y en 1617 gobernador y capitán general. ${ }^{16} \mathrm{Las}$ atribuciones independientemente de la denominación fueron prácticamente las mismas, en cuanto a poseer como máxima autoridad las jurisdicciones: civil, militar y judicial en la provincia. El gobernador estuvo supeditado en materia judicial y fiscal a la Real Audiencia de México, instancia a la que correspondía "conocer"17 las apelaciones de la zona. En materia administrativa y militar el gobernador de

15 Edmundo O'Gorman. Historia de las divisiones territoriales de México (México: Porrúa, 1966).

16 Para efectos prácticos de la investigación, el cargo será denominado de forma genérica gobernador.

17 Se refiere en términos jurídicos procesales, a la facultad de un juez o tribunal de resolver una resolución a la que se le haya interpuesto algún recurso legal como la apelación, revocación, suplicación o segunda suplicación, dando el derecho a la autoridad de dictar una nueva resolución en un sentido que puede: confirmar, revocar o ambas en partes. 
Yucatán gozó de cierta autonomía y grado de discrecionalidad. ${ }^{18}$

Desde el inicio de la colonización se ubicaron productos generados en la región susceptibles de ser comercializados en la capital novohispana, como cuando en 1544 se consignó: "que la provincia de Yucatán es tierra sana y rica en algodón y mantas que se venden en México". ${ }^{19}$ A principios del siglo XVI y de manera efímera, los españoles se allegaron de mano de obra a través de la encomienda ${ }^{20}$ que incluía prestación de servicio profesional, pero ante la prohibición de hacerlo, se diseñaron mecanismos para canalizar este trabajo.

La merced de la encomienda facultaba el cobro de los tributos inherentes al rey y el derecho a acceder a la fuerza de trabajo indígena, aunque al igual que derechos imponía obligaciones, siendo las principales financiar las actividades reli-

18 Woodrow Borah, El juzgado general de indios en la Nueva España (México: Fondo de Cultura Económica, 1996), 353.

19 NYPL: Obadiah Rich Collection Francisco de Montejo, various papers relating to him, his family and the Yucatán, Reel 40, 201. Segundo memorial que para el negocio que en nombre de su Majestad se ha delegado como lo pide el Adelantado Maldonado.

20 En un inicio fue el derecho que la Corona otorgaba a ciertos hispanos (en general conquistadores o sus descendientes) a recibir de los nativos determinada cantidad de los bienes que producían, así como disfrutar gratuitamente de su mano de obra. A cambio de ello, asentaba la ley, debían velar por la cristianización de sus encomenderos y porque vivieran "en policía”, y estar prontos a "defender la tierra" en casos de peligro. Más adelante se quitó a los encomenderos la posibilidad de usufructuar gratuitamente el trabajo indígena, manteniendo solo el derecho de recibir los tributos, pero entre una jurisdicción y otra variaba mucho el cumplimiento de la ley. giosas, consistentes principalmente en la evangelización de los indios y tener bajo su amparo y protección a cierto número de indios para el buen tratamiento de sus personas. $^{21}$

Los trabajos de los indígenas yucatecos consistieron en el llamado servicio personal, con el cual los españoles construían sus casas y edificios de gobierno y religiosos, arreglaban los caminos y fomentaban sus fincas y estancias ganaderas, entre otras muchas cosas. También tuvieron que pagar el tributo anual al rey, más la limosna a los eclesiásticos, obligatoriamente para hombres y mujeres, jóvenes y adultos, solteros, viudos y casados, aunque en distintas cantidades. El tributo fue un reconocimiento de la calidad de vasallos, que generalmente se pagaba en mantas, aves, cera y maíz..$^{22}$

Otras exacciones fueron las limosnas y obvenciones, que se les obligó a pagar a los indígenas incorporados a la Iglesia católica. La finalidad del pago de las limosnas fue el sostenimiento digno de los ministros e iglesias. Por su parte, las obvenciones sirvieron para los servicios religiosos. El pago de estas contribuciones fue elemental para el correcto funcionamiento del sistema colonial en Yucatán.

21 Gabriela Solís Robleda, Bajo el signo de la compulsión. El trabajo forzoso indígena en el sistema colonial yucateco 1540-1730 (México: INAH/CIESAS/Instituto de Cultura de Yucatán/ Miguel Ángel Porrúa, 2003), 43.

22 Mario Humberto Ruz Sosa, Yucatán: un universo peninsular. El mundo colonial, tomo 2 (México: SEP, UNAM, CEPHCIS, 2009), 36-39. 
Las limosnas se impusieron desde la llegada de los primeros religiosos en Yucatán; la responsabilidad del cobro recaía en el Cabildo de Indios y en los indios cargueros de la iglesia. ${ }^{23} \mathrm{El}$ holpatan fue otra carga que se pagaba por el servicio de los defensores de indios en Yucatán, se constituyó en una carga forzosa más entre las varias que pesaban sobre los indios, y consistió en la entrega de un real cada año por tributario. ${ }^{24}$

Con las Leyes Nuevas de 1542 la Corona española cuidó mucho la forma de contratar económicamente con los naturales. Las leyes cubrieron diversos derechos, siendo el principal el reconocimiento de los indios como vasallos del rey, lo cual prohibía cualquier tipo de esclavitud; simbolizarían el triunfo de Las Casas en pro del iusnaturalismo.

Si bien un tercio se dedicaba a la mejora en las condiciones de vida de los indígenas, otros puntos señalarían la reorganización del sistema administrativo americano como la reorganización y funcionamiento del Consejo de Indias, creación de la Audiencia de Lima y de los Confines. ${ }^{25}$

23 Gabriela Solís Robleda, Bajo el signo de la compulsión. El trabajo forzoso indígena en el sistema colonial yucateco 1540-1730 (México: INAH/CIESAS/Instituto de Cultura de Yucatán/ Miguel Ángel Porrúa, 2003), 139-141.

24 Pedro Bracamonte y Sosa y Gabriela Solís Robleda, Espacios mayas de autonomía: el pacto colonial en Yucatán (Mérida: Universidad Autónoma de Yucatán, Consejo Nacional de Ciencia y Tecnología, 1996).

25 Nicolas Balutet, Ensayos sobre la historia española (1516-1939) (Nueva York: Lulu, 2007), 41.
Estas leyes implicaron un alto proteccionismo hacia el indígena, como se observa en una real cédula del 11 de diciembre de 1569, en la cual Francisco de Ferragute, vecino de la ciudad de Mérida, hizo relación al rey de que por medio de las Nuevas Leyes "se prohibía y mandaba que ningún encomendero de indios no tratase ni contratase con los naturales de sus pueblos, ni los cargase con mercadurías ni otras cosas so pena de perdimiento de sus encomiendas y otras penas". En tal virtud que Ferragute acusó ante la Corona que un tal Juan Gómez de la Cámara, vecino de Mérida, tenía en encomienda los pueblos de Cinanché y Eguán, en los cuales trataba y contrataba por sí y por terceras personas con los vecinos naturales, vendiéndoles vinos, cacao y otras mercancías, a trueque de mantas, cera, maíz, aves, pabilo y otras cosas que los naturales hacían, criaban y cogían.

\section{En especial:}

Les habían comprado dos mil fanegas de maíz y las había vendido a ciertos mercaderes para fuera de la dicha gobernación, haciendo cargar a los dichos indios a cuestas y llevar a un puerto de la mar lejos del dicho pueblo donde lo había embarcado en un navío que allí había, todo sin pagarles a los dichos indios su justo valor. ${ }^{26}$

26 AGI, México 2999, L. 2, ff. 233v-234r, Real cédula sobre el buen tratamiento a los indios por parte de los 
No sólo los encomenderos trataron y contrataron con los indios, los gobernadores debieron cuidar este aspecto hacia los naturales, puntualmente existieron normas que específicamente prohibían los excesos.

En un primer momento, conquistadores y encomenderos tomaron de manera forzosa mano de obra indígena e incluso recurrieron a la esclavitud. Así lo revelan las memorias tocantes a la provincia de Yucatán, donde se menciona que el Adelantado Francisco de Montejo como gobernador de Honduras remitió cuadrillas de indios esclavos: "naturales que sacaban oro de las minas teniendo en aquella provincia muchos indios de repartimiento envió su licencia o sin ella entró en Yucatán don Francisco de Montejo su hijo natural". ${ }^{27}$

Esta situación cambió por ley con las disposiciones relativas a la libertad de los indios en las Leyes Nuevas promulgadas en 1542. Para 1567 los indios ya conocían sus derechos, y sabían de los abusos que muchos españoles cometían en su contra, por lo cual, enviaron diversas cartas firmadas por los caciques de cuatro provincias, donde se quejaban con el rey Felipe II de los tormentos y abusos que con ellos habían

encomenderos en Yucatán, Madrid a 11 de diciembre de 1569.

27 NYPL: Obadiah Rich Collection Francisco de Montejo, various papers relating to him, his family and the Yucatán, Reel 40,199. Relación de lo que su Majestad ha mandado se tengan memorias de las cosas tocantes a las provincias de Yucatán, Campeche, Cozumel y Tabasco, 1554. cometido los religiosos de la orden de San Francisco, denunciando que estos habían hecho firmar a varios indios, como si fueran los señores de la tierra, ciertas cartas escritas en castellano en su propia defensa así lo demuestran.

Tal es el caso de las quejas contra fray Diego de Landa a quién identificaron como principal responsable de los abusos cometidos. ${ }^{28}$ Un extracto de una de las cartas de los indios gobernadores de Yucatán, mencionó:

Después que nos vino el bien que fue conocer a Dios nuestro señor por sólo verdadero Dios dejando nuestra ceguedad idolatrías y vuestra majestad por señor temporal antes que abriésemos bien los ojos al conocimiento de lo uno y lo otro nos vino una persecución la mayor que se puede imaginar y fue en el año de 1562 para nos doctrinasen que en lugar de hacerlo nos comenzaron a atormentar colgándonos de las manos y acostándonos cruelmente y colgándonos pesas de piedras a los pies y atormentado a muchos de nosotros en bultos, echándonos mucha cantidad de agua en el cuerpo, de

28 AHN, Diversos-colecciones, 25 N 2, Colección de documentos inéditos de las Indias. Carta de los indios de Yucatán, firmada por los gobernadores de cuatro provincias, en que se quejan a Felipe II de los tormentos y abusos que con ellos habían cometido los religiosos de la orden de San Francisco, Yucatán, 4 de diciembre de 1567. 
Figura 2. Mapa político de la provincia de Yucatán

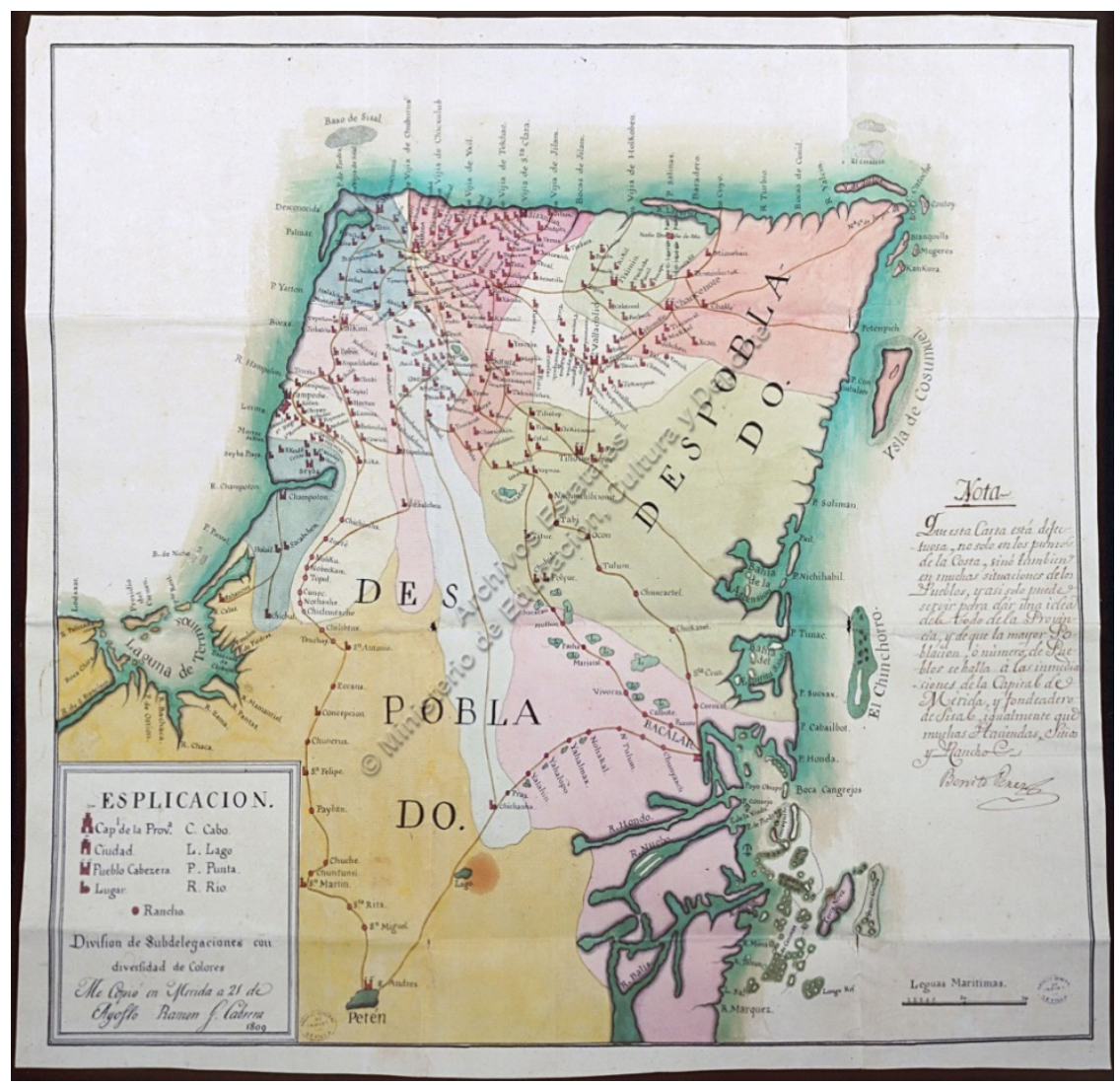

Fuente: AGI, MP-México 756.

los cuales murieron y masacraron a muchos de nosotros. ${ }^{29}$

La política proteccionista, motivó la creación de dos formas separadas de organización social y de gobierno (república de indios y república de españoles). En esta separación se sustentó el funcionamiento del sistema económico en Yucatán, pues la organización social de los pueblos fue la clave que permitió a los colonizadores una administración efectiva de generación de excedentes y las autoridades nativas fue-

29 Ibídem, AHN, Diversos-colecciones, $25 \mathrm{~N}$ 2, foja 1. ron las responsables de controlar la mano de obra de su población sujeta para asegurar el puntual cumplimiento de sus obligaciones fiscales y laborales.

Por pertenecer a una república, sus miembros debieron entregar productos y trabajo y a cambio recibieron el acceso a la tierra de cultivo, los recursos del monte y el agua, solares, ayuda en trabajo, participación en los rituales colectivos, acceso a los servicios religiosos, auxilio en épocas de sequía y escasez alimentaria y otros beneficios. Entonces, la economía en Yucatán dependió del trabajo de los indios y 
se impuso sobre sus principales formas de organización. ${ }^{30}$

Pero más allá de estas formas de organización sociopolítica en repúblicas, es interesante distinguir la compleja relación en el plano del ejercicio del poder entre gobernados y gobernantes. Para ello, y otro tipo de cuestionamientos históricos, resulta indispensable exponer el panorama de la conformación social y político-jurisdiccional de la Península de Yucatán.

\section{Los diversos estatutos jurídicos en Yucatán}

La legislación indiana diferenció a los grupos socio étnicos. Los que se encontraron en la cúspide fueron los peninsulares. Tanto estos como los criollos tuvieron preferencias con respecto a los otros conjuntos. En Yucatán fueron encomenderos comerciantes y estancieros y desempeñaron cargos públicos, tanto políticos como religiosos y judiciales. En la región de estudio fueron los principales beneficiarios -aparte de la Corona y la Iglesia- del trabajo y la producción indígena al recibir tributos, limosnas, servicios personales y géneros contratados por repartimiento. ${ }^{31}$

30 Paola Peniche Moreno, "Migración y parentesco en una parroquia del norte de Yucatán siglo XVIII" en Problemas demográficos vistos desde la historia. Análisis de fuentes, comportamientos y distribución de la población en México, siglos XVI-XIX, de América Molina del Villar (México: CIESAS, 2006), 48.

31 Laura Caso Barrera, Caminos en la selva. Migración, comercio y resistencia. Mayas yucatecos e itzaes, siglos XVII-XIX (México: COLMEX, Fondo de Cultura Económica, 2002), 22.
En Europa se empezó a debatir acerca de la naturaleza y derechos del hombre americano donde se enfrentaron las ideas de Ginés de Sepúlveda y fray Bartolomé de las Casas. Como resultado de la polémica en torno al iusnaturalismo que debía proteger a los indios se generaron legislaciones de protección a favor de la población recién conquistada (Leyes Nuevas 1542), pero en contraparte también se consolidó la idea de servidumbre natural y el tutelaje. ${ }^{32}$

Las distinciones en la legislación eran evidentes, por ejemplo, en materia legislativa las penas contra españoles y criollos eran mucho más blandas, a diferencia de los negros, indios y otras castas. Incluso entre españoles existieron diferencias: el español dueño de ganado que infringió la ley debió pagar una multa de trescientos ducados y cumplir un destierro de dos a cinco años, mientras que el español de humilde condición fue castigado con pena de vergüenza pública y debió pagar una multa de cien ducados para la Cámara Real. ${ }^{33}$

Las leyes, como hemos mencionado, tendieron a ser menos severas contra los españoles en relación con los otros grupos. Por ejemplo, una disposición expresó la diferencia en castigos para negros y mu-

32 Pedro Bracamonte y Sosa, Tiempo cíclico y vaticinios. Ensayo etnohistórico sobre el pensamiento maya (México: CIESAS, Colección Peninsular, Miguel Ángel Porrúa, 2010), 78.

33 Juan Pablo Bolio Ortiz, De las justicias indígenas a las justicias castellanas. Dinámica del proceso judicial en la jurisdicción de Quetzaltenango, Guatemala (17001750) (Tesis de Maestría, CIESAS, 2010), 46. 
latos con relación a ellos, si los afrodescendientes persuadían a un esclavo que se escondiera y lo ocultaban por cuatro meses para efecto de manifestarlo después y apropiárselo, se les imputaba pena de muerte natural, en cambio si los ocultadores eran españoles, se les desterraba de todas las Indias. Otra situación era el derecho a portar armas, que fue exclusivo de españoles, pardos, caciques mayas y mestizos. ${ }^{34}$

Entonces, en la cúspide social se encontraron los españoles. Para ellos se reservaron los cargos gubernamentales y eclesiásticos, así como las encomiendas y las licencias para explotar minas y fundar estancias de ganado, labores agrícolas y obrajes. No tenían obligación de pagar tributo, pero sí otros impuestos, como la alcabala y la media anata. Gozaban de distintos fueros según el grupo al que pertenecían, como el militar y el eclesiástico. ${ }^{35}$ Por otro lado encontramos a los indios, quienes tuvieron una relación con el poder institucional diferente en Yucatán, similar a los casos de Oaxaca y Chiapas con respecto a otras regiones, fue una relación llena de rebeliones, huidas y pactos sociales.

En la gobernación de Yucatán, la fuerza política la tuvieron los encomenderos como el clero en la región. No existió mando intermediario entre los indios de

34 ADLP, Recopilación de Leyes de Indias de 1680. Leyes 14 y 22 , título 5 , Libro 7.

35 Gisela von Wobeser, Historia de México (México: FCE, SEP, Academia Mexicana de Historia, 2010), 105. los pueblos y el gobernador de la provincia entera o sus asistentes inmediatos en Mérida: el defensor o abogado de indios, encargado de asesorar al gobernador en esos asuntos, y el auditor de guerra, su consejero legal..$^{36}$

Parece ser que desde el punto de vista normativo, la política de la Corona para con los indios fue de evitar vejaciones por parte de autoridades y españoles a la población. ${ }^{37}$ Por ejemplo, para 1562 una real cédula para el territorio dependiente de la Real Audiencia de Guatemala (Yucatán estuvo bajo su jurisdicción 13 años, de 15501563) hizo hincapié en lo siguiente: "que la disposición dada por el Licenciado Alonso López de Serrato, sobre que los alcaldes de raza indígena no deben depender de los de raza española sino directamente de la $\mathrm{Au}$ diencia no deben ser derogadas". ${ }^{38}$

No se puede negar la actitud proteccionista hacia el indio por parte de la Corona española. La política de la "máxima ganancia” impidió la aplicación de muchas leyes que resguardaban los derechos de los indios, cómo las Leyes Nuevas de 1542, que se habían dado en el contexto del debate

36 Nancy Farris, La sociedad maya bajo el dominio colonial (México: CONACULTA, INAH, Artes de México, 2012), 126.

37 AGN, Instituciones Coloniales, Indiferente Virreinal, Caja 6488. Real cédula de 1641 hacia las justicias de provincia de Yucatán para que amparen a los naturales de los agravios que reciben de los españoles en sus granjerías.

38 AGCA, A1.23, leg. 1512, fol. 396, Real cédula de 15 de septiembre de 1562 Madrid, sobre que las funciones de los alcaldes indígenas dependan directamente de la Real Audiencia de Guatemala. 
entre Sepúlveda y Las Casas, en el cual el último hizo válida la idea de un iusnaturalismo que debía proteger a todo individuo y quedar bajo la protección de Dios en la tierra, que era el rey. Lo anterior parece significar que a los españoles no les interesó el funcionamiento de las instituciones indígenas, más bien la forma de apropiarse de la producción y mano de obra de los indios.

Con posterioridad, el debate se iría centrando en la sujeción y la libertad, que incluyó cuestionamientos al repartimiento forzoso de mercancías, que contravenían las leyes a la libertad en el ámbito comercial. En especial, las ordenanzas promulgadas por el gobernador Juan de Esquivel en 1663, que prohibían los repartimientos de todos aquellos que tuvieran ascendiente sobre indios, ya fueren gobernadores y sus allegados, ministros, jueces y encomenderos.

Los jueces de los pueblos tenían autorización para detener a quien intentara repartir mercancías, y llevarlos ante el gobernador. En Yucatán el obispo Gómez de Parada, defensor de los naturales, luchó contra el trabajo forzoso indígena, consiguió que se dictara un auto el 30 de abril de 1722 de la Audiencia de México, confirmado el 2 de mayo siguiente, dictando la prohibición de los servicios personales forzosos en la provincia, no obstante, la prohibición enfrentó la oposición de los beneficiarios del trabajo compulsivo. ${ }^{39}$

39 Gabriela Solís Robleda, Bajo el signo de la compulsión. El trabajo forzoso indígena en el sistema colonial yucateco 1540-1730 (México: INAH/CIESAS/Instituto
La estrategia de la Corona era clara a partir de la implantación de las Leyes Nuevas, los indios pasaban a ser vasallos del rey, eliminando la esclavitud. El proyecto consistió en fundar pueblos en los que se reunió a la población nativa, como requisito para la evangelización. En la práctica constituyó un importante elemento de control social encaminado a conseguir los objetivos que el gobierno español pretendió lograr con la población: el control político y el control económico. ${ }^{40}$

En relación con las leyes de protección a los indios, una de las reglas centrales fue que españoles, negros, mestizos, mulatos y pardos no podrían habitar en los pueblos de indios. Consta que, a los gobernadores, como representantes del rey, se les encargó proteger y preservar a la población indígena y cuidar que fuese bien tratada. Esta obligación se consignó tanto en los títulos expedidos con el nombramiento para el cargo como en las directrices para hacer juicio de residencia a sus antecesores. ${ }^{41}$ También se les encargó que cuidaran a los indios, que no anduvieran de vaga-

de Cultura de Yucatán/ Miguel Ángel Porrúa, 2003), 190-208.

40 Paola Peniche Moreno, "Migración y parentesco en una parroquia del norte de Yucatán siglo XVIII" en Problemas demográficos vistos desde la historia. Análisis de fuentes, comportamientos y distribución de la población en México, siglos XVI-XIX, de América Molina del Villar (México: CIESAS, 2006), 75-76.

41 Gabriela Solís Robleda, Entre litigar justicia y procurar leyes. La defensoría de indios en el Yucatán colonial (México: CIESAS Peninsular, Porrúa, 2013), 32. 
bundos, trabajaren y sembraran sus milpas conforme a lo que se ordenaba. ${ }^{42}$

El visitador y oidor de la Real Audiencia de México, Diego García de Palacio, llevó un juicio en el año 1583 por contravenir esta orden, en Valladolid, contra el español Alonso Díaz "por haber vivido entre indios causando gran daño y perjuicio de los naturales de él, donde hizo que le hiciesen una casa de morada y no les pagó por ella cosa alguna". ${ }^{43}$ Otro caso que ilustra los perjuicios que acarreaba esta convivencia con los naturales fue el de Francisco Pinto, en la misma villa, contra quien se hicieron cargos el 16 de diciembre de 1583 por "haber estado amancebado en la provincia de Tizimín con una india, dando mal ejemplo a los naturales de la dicha provincia, y de haber vendido vino a indios contra lo ordenado por Su Majestad".44

Los encomenderos tenían la responsabilidad de evitar el trato entre indios y negros, como lo indica el juicio que siguió el año de 1583 en Tizimín Diego García de Palacio, visitador y oidor de la Real Audiencia de México, contra el encomendero Diego López de Ricalde, por haber permitido que una india tuviera "acceso carnal" con

42 Eusebio Ventura Beleña, Recopilación sumaria de todos los autos acordados de la Real Audiencia y Sala del Crimen de esta Nueva España (México: Universidad Francisco Marroquín, 1787), 40.

43 Diego García de Palacio, Visita de Diego García de Palacio a Yucatán 1583 (México: UNAM, 2009), 155.

44 Diego García de Palacio, Visita de Diego García de Palacio a Yucatán 1583 (México: UNAM, 2009), 173. un negro llamado Ximón, esclavo de un español llamado Juan Dorado. ${ }^{45}$

Otro problema muy presente para la Corona fue evitar maltratos a los indios por parte de los afrodescendientes. Una real cédula de 1722 mencionó este tipo de agravios al referir la propuesta de cancelar el servicio personal forzado, castigando severamente a los gobernadores que diesen mandamientos de ese servicio, "pues hasta los negros esclavos maltratan a los indios haciéndolos de peor condición que ellos y los castigan más que sus mismos amos". ${ }^{46}$

Algunos eclesiásticos, al igual que ciertas autoridades civiles, abusaban y agraviaban a los indios. Fueron continuas las quejas en este sentido, por ejemplo, en 1701 el rey escribió al gobernador de Yucatán en torno a la preocupación por vejaciones pues se había informado "que los religiosos doctrineros de ese gobierno maltratan a los indios y cobran de ellos excesivos derechos parroquiales y otras muchas contribuciones pecuniarias, llevando cada uno de ellos sus testamentos". ${ }^{47}$

Paralelamente, los mayas conservaban libertad para administrarse según sus usos y costumbres, entre ellos, la organización

45 Diego García de Palacio, Visita de Diego García de Palacio a Yucatán 1583 (México: UNAM, 2009), 143.

46 AGI, México 1081, L. 50, ff. 1r-16v, Real cédula dando comisión al obispo de Yucatán para que remedie las vejaciones y malos tratos que se hacen a los indios, Madrid a 28 de noviembre de 1722.

47 AGI, México 1078, L. 40, No. 1, ff. 219r-220r, Real cédula al gobernador de Yucatán en respuesta de una carta suya y diciéndole lo que ha de ejecutar para el mayor alivio y conservación de los indios, Madrid a 19 de julio de 1701. 
territorial fue compleja, las tierras se dividieron en tierras comunales correspondientes a las repúblicas de indios, divididas en jurisdicción política y corporativa: para caza, recolección, labranza y milpas. Las comunales eran administradas por el Cabildo y cacique. Otro tipo de tierras han sido apuntadas por Pedro Bracamonte: las de propiedad privada de los ch'ibales (linajes patrilineales) que se dividían en dos, las de linaje y las de propiedad puramente particular. ${ }^{48}$

En Yucatán las organizaciones llamadas ch'ibales constituyeron una de las células básicas de la estructura social de los mayas desde la época prehispánica, persistiendo hasta finales de la época colonial. El ch'ibal ha sido descrito como un grupo de parientes que proviene de un antepasado común, reconocido e identificado por un patronímico. Para los mayas compartir un patronímico era razón suficiente para que dos individuos se consideraran como parientes y emprendieran entonces acciones colectivas. ${ }^{49}$

Jurídicamente se creó un nuevo orden legal, aquel donde los usos y costumbres indígenas tuvieron que vivir al lado de un sistema administrativo español, que las

48 Pedro Bracamonte y Sosa, Los mayas y la tierra. La propiedad indígena en el Yucatán colonial (México: CIESAS, Colección Peninsular, Instituto de Cultura de Yucatán, Miguel Ángel Porrúa, 2003), 65-59.

49 Paola Peniche Moreno, "Migración y parentesco en una parroquia del norte de Yucatán siglo XVIII" en Problemas demográficos vistos desde la historia. Análisis de fuentes, comportamientos y distribución de la población en México, siglos XVI-XIX, de América Molina del Villar (México: CIESAS, 2006), 292-293. positivó en el derecho indiano. ${ }^{50}$ Debemos considerar que dentro de la sociedad indígena existió una capa social favorecida, la de los indios nobles e hidalgos, a los cuales no necesariamente la riqueza les daba un estatuto sino más bien el linaje, gran cantidad de ellos estaban exentos de la obligación de tributar, tuvieron pactos con autoridades civiles, muchos consiguieron eludir el trabajo forzado y en conjunto, se sustrajeron a las condiciones de los indios macehuales..$^{51}$

Siempre existió gran preocupación por las rebeliones que los indios podrían causar en Yucatán. Se alegaba que, por haber poca población de españoles en la provincia, los indios "con guerras pueden hacer mucho daño en la tierra y con sus idolatrías por el modo que van inficionarla toda." Había en los montes de Yucatán muchos naturales que vivían según sus antiguas costumbres y tenían contacto con los pueblos cristianos, a más de haber muchos sacerdotes de la religión proscrita. Al llegar en 1599 esta información al rey, se ordenó que los indios aquines, que eran "los dogmatizadores de sus idolatrías, como tan perjudiciales”, fueren castigados

50 El derecho castellano fue el legislado en Castilla, el indiano fue el conjunto de normas jurídicas que se aplicaron en Indias, es decir, los territorios de América, Asia y Oceanía dominados por España y por último, el indígena fue el conjunto normas consuetudinarias de las poblaciones indígenas, anteriormente señalados.

51 Juan Pablo Bolio Ortiz, De las justicias indígenas a las justicias castellanas. Dinámica del proceso judicial en la jurisdicción de Quetzaltenango, Guatemala (17001750) (Tesis de Maestría, CIESAS, 2010), 42-43. 
con rigor y graves penas y que reincidiendo tercera vez "sean quemados pues por otros delitos lo son, porque la experiencia ha mostrado que los que dan en semejante vicio nunca se apartan de él”. ${ }^{52}$

Las Leyes de Indias estipularon castigos rigurosos para los encomenderos que vendiesen a sus indios y que los caciques no tuviesen a sus sujetos como esclavos; se mandó además que causas de esclavitud fueran de la competencia de las audiencias y que los obispos avisaran de transgresiones a los defensores de indios..$^{53}$ Esta postura debió seguir incluso para finales del siglo XVIII, dictándose diversas cédulas reales haciendo énfasis en la libertad y los buenos tratos que debían recibir los indios. ${ }^{54}$

En cuanto a la justicia, el proceso judicial sumario era la forma de todo juicio donde intervinieron los indios, como parte de respeto a los usos y costumbres de los pueblos indígenas y la difusión del derecho indiano entre los naturales fueron medidas alentadas por la Corona, con el fin de mejorar el acceso de los indios a la justicia. Por otra, parte, el control de procuradores y su especialización en negocios indígenas también

52 AGI, México 2999, L. 4, f. 600v, Real cédula para que el gobernador de Yucatán informe y haga que los indios no reciban perjuicios, Barcelona a 28 de junio de 1599.

53 ADLP, leyes 1, 2, 3,10 y 15, Título 2, Libro 6 de la Recopilación de Leyes de Indias.

54 AGEY, Fondo Colonial, Caja 22, Volumen 1, Exp. 41, Fojas 2, CD 22, Real cédula expresando cuidar la libertad de los indios, Madrid a 23 de febrero de 1795. constituyeron antecedentes a la creación del cargo de defensor de los naturales. .5

Ahora bien, en cuanto a los afrodescendientes, estos se encontraron en la base social. Las normas para estos grupos abarcaban a los mulatos, pardos y negros, aun entendiendo que los mulatos y pardos eran producto de las castas, la diferencia provino de su calidad de esclavos o libres.

La documentación indica, para el caso de Yucatán, que los afrodescendientes aparecieron en la sociedad colonial yucateca. Uno de los estudios valiosos sobre el tema es el realizado por Matthew Restall, donde propone que en el Yucatán colonial la población de origen africano logró evitar la esclavitud y diversas formas de subordinación racial, esto porque lograron inmiscuirse en la forma de vida de la sociedad española y maya, lo cual generó incluso la idea de una población afro-maya. Restall considera que los afrodescendientes contribuyeron de forma significativa al mestizaje en la región y que hacia 1790 el 12.2\% de la población yucateca era afrodescendiente, concentrándose en una franja desde Campeche, pasando por Mérida y hasta Tizimín. ${ }^{56}$

Se calcula que los afrodescendientes en Yucatán solo fueron traídos como esclavos

55 Caroline Cunill, Los defensores de indios de Yucatán y el acceso de los mayas a la justicia colonial (1540-1600) (Mérida: UNAM, Centro Peninsular en Humanidades y Ciencias Sociales, 2012), 70.

56 Mattew Restall, The Black Middle. Africans, Mayas, and Spaniards in Colonial Yucatan (Stanford: Stanford University Press, 2009). 
en un 5\% del total del comercio esclavista introducido al México colonial, llegando a Campeche desde Veracruz, La Habana, Santo Domingo o Belice. ${ }^{57}$

Algunos documentos revelan la presencia de afrodescendientes en la provincia desde el siglo XVI. Este grupo socio-étnico causó preocupación en Yucatán, especialmente por los perjuicios que podría acarrear su contacto con la población maya. Así lo revela una real cédula del 9 de septiembre de 1551, que consigna habían llegado informes sobre los muchos inconvenientes que se originaban por la entrada de negros en los pueblos de los naturales

y es causa que roben a los indios y les tomen sus mujeres e hijas y me fue suplicado lo mandase también remediar proveyendo que no entrase negro alguno en pueblo de indios en todas las dichas provincias de Yucatán y Cozumel ni que trajesen armas. ${ }^{58}$

La introducción a la provincia yucateca de negros esclavos se puede constatar en los permisos que debían obtenerse de la Corona para hacerlo, como el que se le concedió en 1555 al obispo de Yucatán, Fray Juan de la Puerta, para viajar a su

57 Jorge Victoria Ojeda y Jorge Canto Alcocer, San Fernando Aké: microhistoria de una comunidad afroamericana en Yucatán (Mérida: UADY, 2006), 13.

58 AGI, México 2999, L. 1, ff. 64r-v, Real cédula a la Real Audiencia de Guatemala para que resuelva problemas relativos a Yucatán y Cozumel, Valladolid a 9 de septiembre de 1551. diócesis con cuatro esclavos negros para su servicio personal y se le condonó el pago de los derechos que ello implicaba.59

La presencia de los negros en Yucatán fue un hecho. Para el siglo XVII se hizo mención de presencia de negros en $\mathrm{El}$ Cuyo; ${ }^{60}$ igual en el pueblo de Tixcocob se hablaba de un cuarto de negros y mulatos en $1670 .{ }^{61}$ Robert Patch calculó poca presencia de negros en Mérida en 230, Valladolid 14 y Campeche 1101 para 1779.62

En las Leyes de Indias se estableció que los afrodescendientes pudieran redimirse comprando su libertad ${ }^{63}$. Algunos la obtuvieron durante la segunda mitad del siglo XVII, lo cual creó la idea de una reducción de la esclavitud durante el siglo XVIII y una esclavitud atenuada en las postrimerías coloniales. Es decir, los esclavos dejaron de ser lo que habían sido antes para convertirse en esclavos de confianza, esclavos casi de confianza, esclavos casi patriarcales. No ya trabajadores explotados en grado superlativo y sin ningún in-

59 AGI, México 2999, L. 1, f. 114r, Licencia a Juan de la Puerta para que introduzca 4 negros a la provincia de Yucatán y Cozumel para su persona, Valladolid a 17 de julio de 1555.

60 AGI, México 1068, L. 14, No. 2, ff. 31r-35r, Real cédula al gobernador de Yucatán sobre la fortificación de la villa y puerto de San Francisco de Campeche, Madrid a 12 de febrero de 1648.

61 AGI, México,1070, L. 22, No. 1, ff. 234r-235r, Real cédula al obispo de Yucatán extrañándole no haber puesto edictos a dos beneficios vacos a que le exhortó el gobernador de aquella provincia, Madrid a 4 de febrero de 1670.

62 Robert Patch, Maya and Spaniard in Yucatan, 16481812 (Stanford: Stanford University Press. 1993), 234.

63 ADLP, libro 7, Título 5, ley 81, Recopilación de Leyes de Indias. 
centivo en su trabajo, sino trabajadores a quienes se confió la administración de las haciendas o de ciertos aspectos del trabajo en ellas, del mismo modo que se les permitió vivir en ciertas casas ricas. ${ }^{64}$

Sobre el tema de la esclavitud, Restall propone que en el caso yucateco a lo largo de la colonia fue una "ambigua" sociedad con esclavos, debido a la falta de una agricultura de plantación basada en esclavos y a la poca importación de estos. Los dueños de esclavos fueron la élite dirigente. La libertad se conseguía con alguna regularidad por concesión del amo o por compra del esclavo. Tal situación, generó la casi nula existencia de asentamientos de esclavos huidos. Así, remata que en el Yucatán colonial no existió una clara línea divisoria entre esclavos y libres, pues ambos tenían las mismas ocupaciones y tendían a ser percibidos de manera similar por españoles y mayas, situación que favoreció a que los esclavos disfrutaran las mismas oportunidades que tenían los libres, pero por otro lado contribuyó a mantener un tope para la movilidad social afro-yucateca. ${ }^{65}$

Diversas normas se establecieron para los afrodescendientes. ${ }^{66}$ La regla genérica

64 Severo Martínez Peláez, La patria del criollo. Ensayo de interpretación de la realidad colonial guatemalteca (México: BUAP, 1982), 276-277.

65 Mattew Restall, The Black Middle. Africans, Mayas, and Spaniards in Colonial Yucatan (Stanford: Stanford University Press, 2009).

66 Se prefiere usar este concepto, pues engloba las tres calidades: negros, mulatos y pardos. No por ello se dejan de usar estos términos en el texto cuando nos referimos específicamente a uno de estos grupos. era que no pagaron tributo por su carácter de esclavos, incluso en Yucatán a finales de la época colonial. ${ }^{67}$ Una cédula generalísi$\mathrm{ma}^{68}$ de 1572 , recopilada posteriormente en las Leyes de Indias, ordenó que negros y mulatos libres pagaran tributo al rey. Un mes después, Felipe II estipuló que los hijos de negros esclavos con indias de igual forma estaban obligados a pagar tributo. Se procuraba que los negros se casasen con negras y los esclavos no obtenían la libertad por haber contraído matrimonio. En 1563 se normó que los hijos de españoles y negros lograban obtener la libertad si sus padres los compraban.

Tampoco podían los negros libres o esclavos servirse de los indios. A los negros esclavos se les negó el derecho a acudir a los órganos de justicia, incluso en 1544 se prohibió que los negros anduviesen de noche por las ciudades. ${ }^{69}$

Primeramente, se señaló que los negros y mulatos libres que no tuvieren oficio fueran condenados al trabajo en las minas, y si eran delincuentes el trabajo en las minas serviría a favor de la Real Hacienda. A los negros se les prohibió el uso de armas, con pena de perderlas la primera vez, la se-

67 AGN, Instituciones Coloniales, Indiferente Virreinal, Caja 2972, Carta del intendente interino de Yucatán al Virrey informándole que los negros y mulatos libres por costumbre no pagan ni pagarán tributos, Mérida, Yucatán, 1810.

68 Estas rigieron para todo el territorio indiano (las reunidas en la Recopilación de Leyes de Indias de 1680).

69 ADLP, leyes 1, 2, 5, 6, 7, 8, 12, título 5, libro 7, de la Recopilación de Leyes de Indias de 1680. 
gunda estarían en la cárcel y por tercera, si fueran esclavos, les serían dados cien azotes, y si eran libres destierro perpetuo de la provincia. En el caso de que algún afrodescendientes usara armas contra un español, aunque no lo hubiera herido, por primera vez se le darían cien azotes, clavándole la mano y a la segunda se la cortarían. El derecho de portar armas era prohibido a los negros, mulatos y pardos. ${ }^{70}$

En síntesis, nos referimos a una presencia mínima en la Península con relación a españoles e indios, pero no por ello dejaron de tener una serie de disposiciones jurídicas en torno a su calidad, ya sea de negros, mulatos y pardos libres o esclavos (véase tabla 1 para contrastar).

Tabla 1. Algunos derechos y obligaciones de los diferentes grupos socio-étnicos

\begin{tabular}{|c|c|c|c|}
\hline & Españoles & Indios & $\begin{array}{c}\text { Afrodescendi- } \\
\text { entes }\end{array}$ \\
\hline Tributo & No & Sí & No \\
\hline Alcabala & Sí & No & Sí \\
\hline $\begin{array}{c}\text { Portar } \\
\text { armas }\end{array}$ & Sí & $\begin{array}{c}\text { No, sí } \\
\text { caciques }\end{array}$ & No (pardos sí) \\
\hline $\begin{array}{c}\text { Libertad } \\
\text { Usos y }\end{array}$ & Sí & Sí & Sí redimidos \\
\hline $\begin{array}{c}\text { costumbres } \\
\text { Uso de }\end{array}$ & Sí & Sí & No, sí \\
\hline caballo & caciques & No \\
\hline \begin{tabular}{c} 
Diezmo \\
\hline
\end{tabular} & Sí & Sí & Sí \\
\hline
\end{tabular}

Fuente: Elaboración propia con base en leyes y cédulas en ADLP, AGN y AGI.

70 ADLP, leyes 4, 7, 12 y 14, título 5, libro 7, de la Recopilación de Leyes de Indias de 1680.
Finalmente tenemos a los mestizos, los cuales surgieron como una consecuencia lógica del proceso de conquista y colonización. Los españoles en un principio no llevaron a sus mujeres, por lo que algunos contrajeron nupcias o establecieron relaciones de concubinato con mujeres indígenas, a más de contactos ocasionales que derivaban en el nacimiento de una criatura. A los enlaces de españoles e indios pronto se sumaron las uniones con gente afrodescendiente, que dieron como resultado la aparición de mulatos, pardos y zambos.

De esta variedad de tipos de relación que dio origen al grupo mestizo, se puede deducir el carácter social -más que racial- de este grupo, pues un niño no reconocido por su padre español, que creciese en el entorno maya, quedaría clasificado como indígena, en tanto que si el padre lo reconocía se ubicaría en el mundo español, aun cuando fuere en desventaja por su condición de "hijo natural".

Los mestizos eran artesanos, jornaleros o pequeños comerciantes; también participaron en la milicia. ${ }^{71}$ Dado que los mestizos, mulatos y negros carecieron de derechos corporativos, como en efecto tuvieron los indios, muchas veces se diluyeron en los pueblos de indios, "indianizándose” no en sentido biológico, sino jurídico y posiblemente cultural. Numerosos caciques y

71 Laura Caso Barrera, Caminos en la selva. Migración, comercio y resistencia. Mayas yucatecos e itzaes, siglos XVII-XIX (México: COLMEX, Fondo de Cultura Económica, 2002), 61-62. 
principales se hispanizaron prontamente, se les denominó ladinos. Los mestizos se encontraron en ventaja con respecto a los indios, no así con los españoles o criollos; no estuvieron obligados a tributar y tuvieron libertad para trasladarse a vivir de un lugar a otro.

Por otra parte, no se les permitió acceder a cargos públicos, tuvieron vedadas ciertas ocupaciones y las penas para un mismo delito eran más duras si el reo perteneció a una casta. El ordenamiento jurídico encuadró rígidamente a los mestizos por sobre los indios y por debajo de españoles y criollos. ${ }^{72}$

Los mestizos provinieron tanto de uniones legalizadas como de uniones ocasionales, en cuyo caso su acomodo dentro de la sociedad dependió de las circunstancias de la madre o del reconocimiento que el padre podía darle: la misma posibilidad tenían de figurar entre los tributarios de un pueblo de indios que entre los vecinos de una fundación española, o alimentando el informe de masa de "vagos", que eran solo gente sin "identificación formal y con un espíritu libre que preocupó a las autoridades". ${ }^{73}$

En los pueblos de indios se estipuló con toda claridad prohibición para que mestizos accedieran a los puestos de alcaldes o gobernador de indios, "se haga indispen-

72 Severo Martínez Peláez, La patria del criollo. Ensayo de interpretación de la realidad colonial guatemalteca (México: BUAP, 1982), 268-269.

73 Bernardo García Martínez, Los años de conquista en Nueva Historia de México (México: COLMEX, 2014), 203-204. sablemente en indios puros de padre y madre y que nunca pueda hacer en mestizos, mulatos o cuarterones". ${ }^{74}$ También se estableció que a todos los mestizos, mulatos y negros libres se les pusiera a ayudar a los indios para alivianar el imponderable trabajo. ${ }^{75}$

\section{La configuración poblacional en Yucatán}

Resulta imprescindible conocer al cúmulo social que habitó la gobernación de Yucatán, para así tener una perspectiva general de las personas que la conformaron.

\section{Datos poblacionales}

La conquista de México se cristalizó en el siglo XVI en 1521, con la caída de México-Tenochtitlan, aunque se inició unos años antes en algunas partes del territorio que se llamó Nueva España. Un impacto drástico para la población conquistada fue la introducción de nuevas patologías, ajena hasta entonces para los pobladores nativos de América. Los denominados indios, término por demás arbitrario, quedaron vinculados a pandemias, epidemias y endemias, cuya propagación fue facili-

74 Eusebio Ventura Beleña, Recopilación sumaria de todos los autos acordados de la Real Audiencia y Sala del Crimen de esta Nueva España (México: Universidad Francisco Marroquín, 1787), 206.

75 Julio César Méndez Montenegro, Autos Acordados de la Real Audiencia de Guatemala 1561-1807. Documentos Inéditos para la Historia del Derecho Indiano Criollo (México: B. COSTA-AMIC, 1976), 170. 
tada por el nuevo sistema económico impuesto. $^{76}$

La población indígena pronto se vio afectada por las nuevas enfermedades que los españoles les transmitieron, teniendo una gran susceptibilidad a los nuevos virus de los cuales no eran inmunes. Algunas de las principales estimaciones poblacionales continentales en el primer contacto con europeos se expresan en la tabla 2.

Tabla 2. Cálculos sobre la población continental antes de la llegada de los europeos

\begin{tabular}{|c|c|c|}
\hline Sapper & $\mathbf{3 7 4 8 5 0 0 0}$ & $\mathbf{1 9 2 4}$ \\
\hline Spiden & 40000000 & 1928 \\
\hline Rivert & 13000000 & 1930 \\
\hline Kroeber & 8400000 & 1939 \\
\hline Steward & 15590000 & 1949 \\
\hline Rosenblat & 13385000 & 1954 \\
\hline Borah & 100000000 & 1964 \\
\hline Dobyns & 90000000 & 1966 \\
\hline Morner & 33300000 & 1967 \\
\hline Chaunu & 80000000 & 1969 \\
\hline
\end{tabular}

Fuente: Malvido, 2002, 22.

La sociedad maya tuvo que enfrentar diversas calamidades, incluso antes de la llegada de los europeos. Landa refiere la llegada de un huracán que causó estragos en la población, calenturas pestilenciales, guerras por la caída de Mayapán, plagas y

76 Elsa Malvido, "La población, siglos XVI al XX" en Historia Económica de México, editado por Enrique Semo y Elsa Malvido (México: UNAM, Océano, 2000), 24-25. una peste de "grandes granos que les pudrían el cuerpo con gran hedor, de manera que se les caían los miembros a pedazos en tres o cuatro días".77

La población indígena en la Península de Yucatán disminuyó de manera drástica durante todo el primer siglo. Al conquistar Yucatán, Francisco de Montejo pobló Mérida como ciudad capital con setenta vecinos encomenderos de indios, y tres villas: la de Valladolid, con cuarenta, la de Salamanca de Bacalar con veinte y la de San Francisco de Campeche con otros veinte. Para ser considerado vecino debía cumplirse ciertos requisitos y tener registro formal en los libros de los ayuntamientos, pues otros habitantes podían tener diversas categorías como residentes. $^{78}$ La numerosa población originaria que encontraron los españoles disminuyó por diversas causas: la guerra de conquista, el choque cultural, enfermedades, epidemias, hambres, viruelas y otras pestilencias. ${ }^{79}$ Se han elaborado cálculos en cuanto a la población durante la colonia en Yucatán que varían en gran medida.

A fines del siglo XVI en Yucatán siguió muy arraigada la idea de que las encomiendas proporcionaban mucha honra,

77 Diego de Landa, Relación de las cosas de Yucatán (Mérida: Sureste, Dante, 2010), 34-35.

78 Bernardo García Martínez, "Los años de conquista" en Nueva historia mínima de México (México: COLMEX, 2014), 201.

79 Mercedes de la Garza, Relaciones histórico-geográficas de la gobernación de Yucatán (México. México: UNAM, Fuentes para el estudio de la cultura maya, 1983), 66-71. 
estimación y autoridad a los que llegaron a conseguirlas. Al caducar el siglo XVI, Mérida contó con más de 300 vecinos. Es indudable que las desfavorables condiciones económicas de la provincia determinaron que en ella se mantuvieran estructuras sociales marcadas por las cuestiones sociales, económicas y políticas. ${ }^{80}$

La población indígena en Yucatán disminuyó de manera drástica durante el siglo XVI (Farris, 2012, 86-88), por lo que el contacto con los europeos significó una brusca caída, tendencia que se mantuvo hasta el siglo XVII. Gerhard apreció que habría 265,000 habitantes mayas en 1550 y sólo 150,000 hacia 1600 . Cook y Borah calcularon 233,776 indígenas para $1549 .{ }^{81}$

Para 1688 Mérida reunía una cantidad de indígenas y vecinos que se estimó en 8,000 y 10,000 individuos, es decir más del doble de los que albergaba un siglo antes (García Bernal, 2005, 102). Para finales del siglo XVIII, Humboldt consignó 28,393 habitantes (Humboldt, 1969, 38), o sea que prácticamente en cien años Mérida triplicó su población. En 1807 el gobernador estimó 30,000 habitantes para Mérida, en tanto que Valladolid registraba 11,860 en 1784 ,

80 María Cristina García Bernal, Economía, política y sociedad en el Yucatán colonial (Mérida: UADY, 2005), $392-401$.

81 Sherbune Cook y Borah Woodrow, Ensayos sobre historia de la población: México y el Caribe (México: FCE, 1998), 35-40. siendo desplazada por Campeche que ese mismo año contó 16,940 habitantes. ${ }^{82}$

La configuración social de las tres villas en Yucatán fue diversa, en ellas afloró la rígida jerarquización social que en Mérida y Valladolid existió, cuya cúspide había sido asumida por la clase encomendera. Así, la aristocracia encomendera estuvo en un primer plano, mostrándose el resto de la población claramente relegada a un segundo plano. La familia, nuclear y extensa, fue la base de toda la organización social. Los porcentajes más altos de población española se ubicaron en los distritos de Mérida y Campeche, seguidos por Valladolid y Bacalar.

La población hacia 1700 se vislumbraba en 185,000 indígenas, cantidad que ascendió a 380,000 en el año de la Independencia. Por otro lado, la población no indígena, explica Gabriela Solís: "se estimó en 1,500 para 1550, un siglo después para 1650, se calculó en 8,400; en 1700 la cantidad asciende a 21,250 y en 1821 se calcula una población de 120,000". ${ }^{83}$ De acuerdo al censo de 1811, los indios representaban el $76 \%$ de la población, mientras que los no

82 Manuel Miño Grijalva, El mundo novohispano. Población, ciudades y economía, siglos XVII y XVIII (México: FCE, COLMEX, 2001), 102.

83 Gabriela Solís Robleda, Bajo el signo de la compulsión. El trabajo forzoso indígena en el sistema colonial yucateco 1540-1730 (México: INAH/CIESAS/Instituto de Cultura de Yucatán/ Miguel Ángel Porrúa, 2003), 14-15. 
Figura 3. Población total de Yucatán, 1610-1794

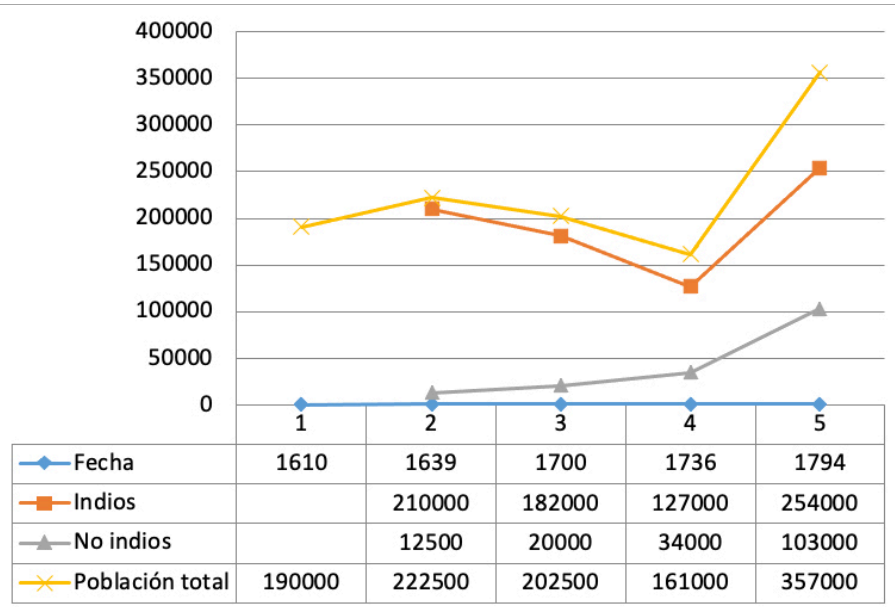

Fuente: Elaboración propia con base en Cook y Borah, Ensayos sobre historia...pp.119-120.

indios conformaban otro $30 \% .^{84}$ (Véase tablas 3, 4 y figura 3).

Tabla 3. Población en Yucatán en la época colonial

\begin{tabular}{|c|c|c|c|c|}
\hline Población & $\mathbf{1 5 5 0}$ & $\mathbf{1 6 0 0 - 1 6 5 0}$ & $\mathbf{1 7 0 0}$ & $\mathbf{1 8 1 0 - 1 8 2 1}$ \\
\hline Indígena & 265000 & 150000 & 185000 & 380000 \\
\hline $\begin{array}{c}\text { No } \\
\text { indígena }\end{array}$ & 1500 & 8400 & 21250 & 120000 \\
\hline
\end{tabular}

Fuente: Gerhard, 1991.

Tabla 4. Población de Yucatán entre 1610-1794

\begin{tabular}{|c|c|c|c|}
\hline Fecha & Indios & No indios & Población total \\
\hline $\mathbf{1 6 1 0}$ & & & 190000 \\
\hline $\mathbf{1 6 3 9}$ & 210000 & 12500 & 222500 \\
\hline $\mathbf{1 7 0 0}$ & 182000 & 20000 & 202500 \\
\hline $\mathbf{1 7 3 6}$ & 127000 & 34000 & 161000 \\
\hline $\mathbf{1 7 9 4}$ & 254000 & 103000 & 357000 \\
\hline
\end{tabular}

Fuente: Cook y Borah, 1998, 119.

La figura 3 expresa cómo la población en Yucatán tuvo una baja considerable, si se comparan las cifras que algunos estudiosos ofrecen de la población antes de la conquista, es interesante ver cómo disminuye la curva poblacional en el siglo XVII y primera mitad del siglo XVIII. La recuperación, tanto de indios y no indios como de la población total, se demuestra con claridad en la primera mitad del siglo XVIII.

Podemos decir que la población de Yucatán tuvo un marcado descenso entre 1550 y 1601; después se recuperó de manera rápida en los siguientes 40 años, hasta alcanzar en 1643 el nivel que tuvo hacia mediados del siglo XVI. ${ }^{85}$

84 Alicia del Carmen Sánchez Contreras, Población, economía y empréstitos en Yucatán a fines de la época colonial (Tesis de Doctorado, COLMICH, 2004), 146.

85 Manuel Miño Grijalva, El mundo novohispano. Población, ciudades y economía, siglos XVII y XVIII (México: FCE, COLMEX, 2001), 104. 
Tabla 5. Estructura de la población de Yucatán por distritos políticos, 1779

\begin{tabular}{|c|c|c|c|c|c|c|}
\hline & Total población & Españoles & Pardos & Negros & Mestizos & Indios \\
\hline Campeche & 23479 & 5211 & 4033 & 1101 & 3070 & 10064 \\
\hline Mérida & 15821 & 3311 & 1774 & 230 & 4351 & 6155 \\
\hline Valladolid & 11332 & 1008 & 694 & 14 & 1066 & 8550 \\
\hline Bacalar & 4025 & 432 & 208 & 55 & 292 & 3038 \\
\hline Tizimín & 11771 & 459 & 1534 & 14 & 900 & 8864 \\
\hline
\end{tabular}

Fuente: Patch, 1993, 234.

Figura 4. Estructura de la población de Yucatán por distritos políticos, 1779

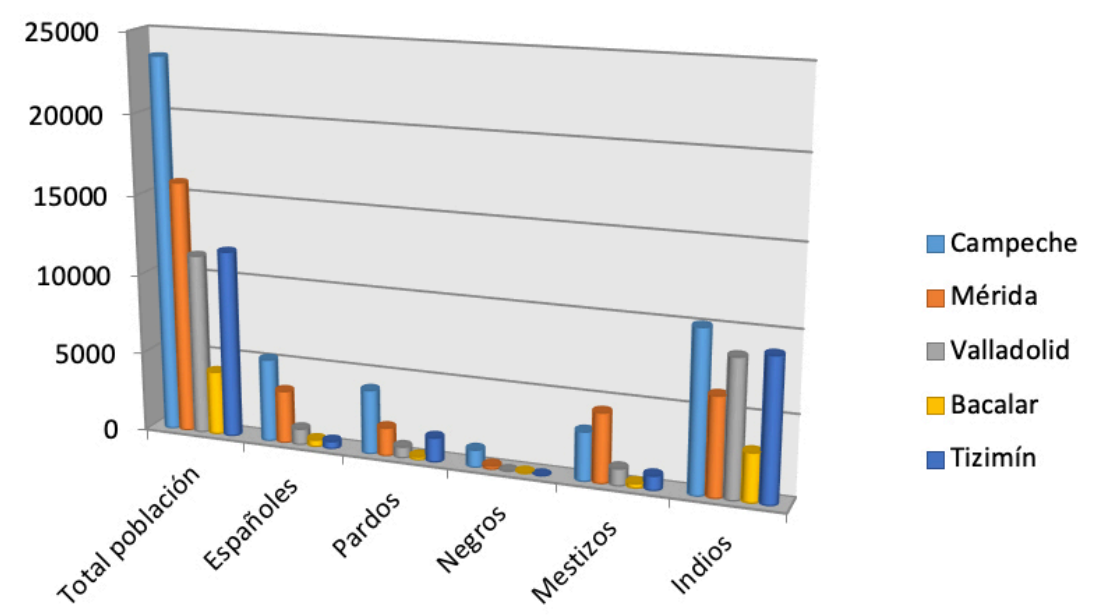

Fuente: Elaboración propia con base en Robert W. Patch, Maya and Spaniard in Yucatan, p. 234

En términos demográficos es importante tener en cuenta el problema que representaron los indios huidos. En la década de 1630 se hablaba de la existencia de más de 30,000 fugitivos de la provincia de Yucatán que habían escapado hacia la zona de la montaña, término utilizado en la documentación colonial para referirse a aquellos indios que se encontraban en territorios fuera de la administración y el control de españoles, otros documentos la denominan como "los montes". En las décadas siguientes se calculó que esa población osciló entre 15,000 y 20,000. La fuga de los indios a "la montaña" fue un proceso constante durante los siglos XVI, XVII y XVIII, situación que acarreó sublevaciones, motines, conspiraciones y revueltas. ${ }^{86}$

86 Pedro Bracamonte y Sosa, La conquista inconclusa de Yucatán: los mayas de las montañas, 1560-1680 (México: CIESAS, Miguel Ángel Porrúa, 2001), 15. 
Tabla 6. Epidemias y hambrunas en el Yucatán colonial, 1535-1810

\begin{tabular}{|c|c|c|c|}
\hline Años & Sucesos & Años & Sucesos \\
\hline $1535-1541$ & Hambruna & 1699 & Epidemia \\
\hline 1564 & Sequía & 1700 & Hambruna \\
\hline 1566 & Epidemia & $1726-1727$ & Hambruna, epidemia \\
\hline $1569-1570$ & Epidemia & 1730 & Hambruna \\
\hline $1571-1572$ & Hambruna & 1742 & Hambruna \\
\hline $1575-1576$ & Epidemia y hambruna & $1765-1768$ & Hambruna (huracán) \\
\hline 1604 & Hambruna & $1769-1774$ & Hambruna (langosta) \\
\hline 1609 & Epidemia (tifo) & 1787 & Hambruna \\
\hline 1618 & Hambruna (langosta) & 1795 & Hambruna \\
\hline $1627-1631$ & Hambruna & 1799 & Epidemia \\
\hline $1648-1650$ & Epidemia (fiebre amarilla) & $1800-1804$ & Hambruna (sequía) \\
\hline $1650-1653$ & Hambruna & 1807 & Hambruna (huracán) \\
\hline 1659 & Epidemia (sarampión) & $1809-1810$ & Hambruna, epidemia \\
\hline $1692-1693$ & Hambruna y epidemia & & \\
\hline
\end{tabular}

Fuente: Farris, 2012, 94.

Las calamidades que se registraron a lo largo de la época colonial estuvieron marcadas por el hierro de las epidemias, como se observa en la tabla 6. El encuentro entre dos poblaciones con historias distintas de adaptación a agentes patógenos, constituyó el factor que desencadenaba severas disrupciones que amenazaban la subsistencia física y la reproducción social de la población nativa.

De tal suerte, la inmunodeficiencia es una variable ineludible para comprender la vulnerabilidad de la población indígena a los efectos de las calamidades, la cual, desde luego, debe ser analizada en conjunto con otros elementos, como los mecanismos iniciales empleados por el colonialismo para integrar a la población indígena. ${ }^{87}$

Como se desprende de la figura 4, para finales del siglo XVIII la población en las principales poblaciones de Yucatán fue variada, la mayor presencia de negros y pardos estuvo en Campeche; Valladolid fue la tercera en población total, teniendo mayoría de indios, seguida de españoles y mestizos. En Mérida principalmente fueron mestizos e indios, en Bacalar la presencia indígena tuvo mayor representación, lo mismo que en Tizimín; la ciudad con ma-

87 Paola Peniche Moreno, Tiempos aciagos. Las calamidades y el cambio social del siglo XVIII entre los mayas de Yucatán (México: Colección Peninsular, CIESAS, 2010), 298-299. 
yor cantidad de españoles fue la capital de Yucatán (véase tabla 6 y figura 4).

\section{Consideraciones finales}

De lo expuesto en este artículo se pueden destacar algunos hallazgos sobre la configuración de la sociedad en la gobernación de Yucatán. La idea fue presentar datos duros y cruzarlos con los datos cualitativos para tener un panorama lo más amplio posible de la configuración social. Con ello damos respuesta a las preguntas planteadas en este trabajo ¿Cuáles fueron los derechos de las personas ante las autoridades e instituciones? ¿Qué tan heterogénea fue la sociedad yucateca de la colonia?

Un primer hallazgo es que la población en Yucatán sufrió grandes cambios debido a coyunturas como la conquista, guerras, epidemias y calamidades, logrando una recuperación lenta para el siglo XVIII. Hacia 1610 la población total rondó los 190,000 habitantes, para 1700 se estimó en 225,000 y para 1794 fueron 357,000 . Estos datos demográficos nos permiten recrear una sociedad que fue cambiando con el paso del tiempo, donde no sólo estuvieron indios y españoles, sino un conglomerado pluriétnico, en la cual convivieron diversas castas que surgieron de la combinación de indios, españoles y negros. Esta recreación resulta fundamental para conocer quiénes fueron las personas durante la época colonial en Yucatán.
Otro hallazgo tiene que ver con los estatutos jurídicos establecidos en la gobernación de Yucatán; españoles y criollos se encontraron en el punto más alto de la jerarquía social yucateca, siendo encomenderos y obteniendo puestos públicos, militares, políticos, religiosos y judiciales; los indios gozaron de cierta autonomía en sus repúblicas prohibiéndoseles la presencia de españoles y otros grupos, se respetó el derecho consuetudinario maya. Con la coyuntura de las Leyes Nuevas de 1542 se estableció la libertad de los naturales, creando una tendencia de parte de la Corona Española al proteccionismo y resguardo de sus derechos. Por último, estaban los afrodescendientes, quienes fueron introducidos por comerciantes, dependieron de su calidad de libres o esclavos, se encontraban en la peor situación jurídica, las penas a estos eran mayúsculas, no se les permitió usar caballos y generalmente fueron usados en los trabajos más arduos, aunque como observamos en Yucatán, la propuesta de Restall señala que los afrodescendientes lograron evitar en gran medida la esclavitud debido al propio sistema económico yucateco.

Otra consideración sería la relativa al poder. Éste tuvo como máximo depositario del poder político y de justicia al gobernador de Yucatán. El poder se ejerció a través de jurisdicciones, que como se ha señalado fueron complejas y deben ser observadas de forma circular, se dividie- 
ron en tres grandes rubros: la religiosa, la suprema y la de los pueblos. En ellas confluyeron autoridades como el gobernador, el cacique, alcaldes y obispos, entre otros, que debieron ejercer el poder jurisdiccional en los territorios puestos a su mando. Cada jurisdicción tuvo sus alcances y sus límites, derechos y obligaciones estipulados por leyes y cédulas reales, todas necesarias para echar a andar el andamiaje normativo, político e institucional de una sociedad compleja, compuesta de conquistados y conquistadores, encomenderos e indios, autoridades políticas y religiosos, caciques, negros, esclavos. Todos son elementos necesarios para comprender que esta historia nos puede llevar más allá de los marcos jurídicos para entender símbolos, prácticas, mentalidades y representaciones de la configuración social y política de la gobernación de Yucatán durante la época colonial.

Por último, resaltamos la importancia de estudiar los procesos históricos en la larga duración, pues ello nos permite entender qué tanto ha cambiado el sistema de gobierno en una región determinada, qué elementos se conservan y cuáles son el resultado de un pluralismo cultural y social propio de todo grupo humano. Es decir, visualizar los cambios y continuidades que sufrió el sistema normativo yucateco para comprender sus alcances.

\section{Bibliografía}

Fuentes primarias

Monografías

Bracamonte y Sosa, Pedro. Los mayas y la tierra. La propiedad indígena en el Yucatán colonial. México: CIESAS, Colección Peninsular, Instituto de Cultura de Yucatán, Miguel Ángel Porrúa, 2003.

Bracamonte y Sosa, Pedro. Tiempo cíclico y vaticinios. Ensayo etnohistórico sobre el pensamiento maya. México: CIESAS, Colección Peninsular, Miguel Ángel Porrúa, 2010.

Bracamonte y Sosa, Pedro y Gabriela Solís Robleda. Espacios mayas de autonomía: el pacto colonial en Yucatán. 1a ed. Mérida: Universidad Autónoma de Yucatán, Consejo Nacional de Ciencia y Tecnología, 1996.

Braudel, Fernand. Aportación de la historia de las civilizaciones: la historia y las ciencias sociales. Madrid: Alianza, 1968.

Caso Barrera, Laura. Caminos en la selva. Migración, comercio y resistencia. Mayas yucatecos e itzaes, siglos XVII-XIX. México: COLMEX, Fondo de Cultura Económica, 2002.

Cook, Sherbune y Woodrow Borah. Ensayos sobre historia de la población: México y el Caribe. México: FCE, 1998.

Cunill, Caroline. Los defensores de indios de Yucatán y el acceso de los mayas a la justicia colonial (1540-1600). Mérida: UNAM, Centro Peninsular en Humanidades y Ciencias Sociales, 2012.

De la Garza, Mercedes. Relaciones histórico-geográficas de la gobernación de Yucatán, México. 
México: UNAM, Fuentes para el estudio de la cultura maya, 1983.

De Landa, Diego. Relación de las cosas de Yucatán. Mérida: Sureste, Dante, 2010.

Elliot, John. España y su mundo, 1500-1700. Madrid: Alianza, 1991.

Farris, Nancy. La sociedad maya bajo el dominio colonial. México: CONACULTA, INAH, Artes de México, 2012.

García Bernal, María Cristina. Economía, política y sociedad en el Yucatán colonial. Mérida: UADY, 2005.

García de Palacio, Diego. Visita de Diego García de Palacio a Yucatán 1583. México: Primera edición, Edición anotada y crítica de Inés Ortiz Yam y Sergio Quezada, UNAM, 2009.

García Martínez, Bernardo. Los años de conquista, en Nueva historia mínima de México. México: COLMEX, 2014.

Gerhard, Peter. La frontera sureste de la Nueva España. México: Instituto de Investigaciones Históricas, Instituto de Geografía, Universidad Nacional Autónoma de México, 1991. Gómez Granillo, Moisés. Breve historia de las doctrinas económicas. México: Esfinge, 1996.

Humboldt, Alexander von. Ensayo político sobre el Reino de la Nueva España. México: Porrúa, 1969.

Martínez Peláez, Severo. La patria del criollo. Ensayo de interpretación de la realidad colonial guatemalteca, séptima edición. México: BUAP, 1982.

Méndez Montenegro, Julio César. Autos acordados de la Real Audiencia de Guatemala 1561-1807. Documentos inéditos para la histo- ria del derecho indiano criollo. México: B. Costa-Amic, 1976.

Miño Grijalva, Manuel. El mundo novohispano. Población, ciudades y economía, siglos XVII y XVIII, Fideicomiso Historia de las Américas, serie Hacia una nueva historia de México. México: FCE, Colmex, 2001.

O'Gorman, Edmundo. Historia de las divisiones territoriales de México. México: Porrúa, 1966.

Patch, Robert. Maya and Spaniard in Yucatan, 1648-1812. Stanford: Stanford University Press, 1993.

Peniche Moreno, Paola. Tiempos aciagos. Las calamidades y el cambio social del siglo XVIII entre los mayas de Yucatán. México: Colección Peninsular, CIESAS, 2010.

Restall, Mattew. The Black Middle. Africans, Mayas, and Spaniards in Colonial Yucatan. Stanford: Stanford University Press, 2009.

Ruz Sosa, Mario Humberto. Yucatán: un universo peninsular. El mundo colonial. Tomo 2. México: SEP, UNAM, CEPHCIS, 2009.

Solís Robleda, Gabriela. Bajo el signo de la compulsión. El trabajo forzoso indígena en el sistema colonial yucateco 1540-1730. México: INAH/CIESAS/Instituto de Cultura de Yucatán/ Miguel Ángel Porrúa, 2003.

Solís Robleda, Gabriela. Entre la tierra y el cielo: religión y sociedad en los pueblos mayas del Yucatán colonial. México: CIESAS, Miguel Ángel Porrúa, 2005.

Solís Robleda, Gabriela. Entre litigar justicia y procurar leyes. La defensoría de indios en el Yucatán colonial. México: CIESAS Peninsular, Porrúa, 2013. 
Victoria Ojeda, Jorge y Jorge Canto Alcocer. San Fernando Aké: microhistoria de una comunidad afroamericana en Yucatán, volumen 24 de Libros Científicos. Mérida: UADY, 2006.

Wobeser, Gisela von. Historia de México. México: FCE, SEP, Academia Mexicana de Historia, 2010.

\section{Tesis}

Bolio Ortiz, Juan Pablo. De las justicias indígenas a las justicias castellanas. Dinámica del proceso judicial en la jurisdicción de Quetzaltenango, Guatemala (1700-1750). Tesis de Maestría, CIESAS, 2010.

Sánchez Contreras, Alicia del Carmen. Población, economía y empréstitos en Yucatán a fines de la época colonial. Tesis de Doctorado, COLMICH, 2004.

Archivos

AGCA: Archivo General de Centro América

AGEY: Archivo General del Estado de Yucatán

AGI: Archivo General de Indias

AGN: Archivo General de la Nación

ADLP: Archivo Digital de la Legislación del Perú

AHN: Archivo Histórico Nacional

NYPL: Biblioteca Pública de Nueva York

\section{Fuentes secundarias}

Malvido, Elsa. La población, siglos XVI al XX

en Historia Económica de México, editado por Enrique Semo y Elsa Malvido. México: UNAM, Océano, 2000, 253.

Peniche Moreno, Paola. Migración y parentesco en una parroquia del norte de Yucatán siglo XVIII en Problemas demográficos vistos desde la historia. Análisis de fuentes, comportamientos y distribución de la población en México, siglos XVI-XIX, editado por América Molina del Villar. México: CIESAS, 2006, 285-315.

Ruz Sosa, Mario Humberto. Nombrar para habitar: la morada maya en las grafías coloniales en Nah, Otoch. Concepción, factura y atributos de la morada maya, editado por Fabienne de Pierrebourg y Mario Humberto Ruz Sosa. Izamal: UNAM, SEGEY, 2014, 259.

Ventura Beleña, Eusebio. Recopilación sumaria de todos los autos acordados de la Real Audiencia y Sala del Crimen de esta Nueva España. México: Universidad Francisco Marroquín, 1787. 